\title{
Pharmacognostical-physico-chemical Evaluation and Development of HPTLC Finger print for Cichorium intybus L. fruits
}

\author{
Achintya Kumar Mandal, Shakila Ramachandran*, Kallingilkalathil Gopi Divya, Mattumal Rubeena, Koppala \\ Narayana Sunil Kumar, Parameswaran Sathiyarajeswaran
}

\section{Achintya Kumar Mandal, Shakila Ramachandran*, Kallingilkalathil Gopi Divya, Mattumal Rubeena, Koppala Narayana Sunil Kumar, Parameswaran Sathiyarajeswaran}

\section{Siddha Central Research Institute (Central Council for Research in Siddha, Ministry of AYUSH), Arignar Anna Hospital Campus, Arumbakkam, Chennai-600 106, Tamil Nadu, INDIA. \\ Correspondence}

Shakila Ramachandran

Siddha Central Research Institute (Central Council for Research in Siddha, Ministry of AYUSH), Arignar Anna Hospital Campus, Arumbakkam, Chennai-600 106, Tamil Nadu, INDIA.

Phone no : 09840715422

E-mail: shakilasiva@gmail.com

History

- Submission Date: 18-01-2018,

- Review completed: 07-03-2018.

- Accepted Date: 12-04-2018

DOI : 10.5530/pj.2018.4.115

Article Available online

http://www.phcogj.com/v10/i4

Copyright

(C) 2018 Phcog.Net. This is an openaccess article distributed under the terms of the Creative Commons Attribution 4.0 International license.

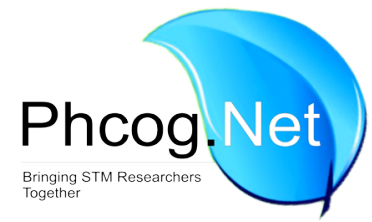

\begin{abstract}
Introduction: Many herbal medicines are lacking pharmacognostical, phytochemical, pharmacological and toxicological data even though used widely for medicinal purposes. Cichorium intybus L. (Asteraceae) - chicory is an ancient folklore medicine. Various parts of these plants are in use for a wide range of ailments including those affecting liver and kidney. The aim of the current study is to standardize the fruit of C. intybus for macroscopy, microscopy, physicochemical parameters, TLC photo documentation along with development of HPTLC fingerprint profiles. Methods: Following standard pharmacopoeial procedures, detailed macro-microscopic characterization along with preliminary phytochemical features of the drug has been recorded from the current study. Results: Macro-microscopic study has revealed the authenticity of this medicinal achene type fruit. Physico-chemical and HPTLC studies revealed constants for identification and authentication of fruits of $C$. intybus. Conclusion: The current study will serve as a reference tool for quality maintenance, authentication as well as scientific validation of chicory fruits.
\end{abstract}

Key words: Chicory fruits, Monograph, Quality control, Standardization.

\section{INTRODUCTION}

Traditional system of medicines is the major backbone of primary health care systems throughout the whole world even in this century. The genus Cichorium comprises of six species majorly distributed in Asia and Europe. ${ }^{1,2}$ C. intybus L. is an erect perennial herb with a fleshy taproot up to $75 \mathrm{~cm}^{2,3}$ It has a very pronounced history in folklore medicine as a very familiar plant in traditional system of medicine in Europe and Asia. Despite this fact, this plant is not described in European pharmacopoeia. ${ }^{4}$ Chicory contains many medicinally important phytochemicals which belong to the categories, viz., carbohydrates, alkaloids, flavonoids, triterpenoids, tannins, fatty acids, volatile oils, etc. ${ }^{5}$ The seed (botanically achene type of indehiscent fruit) contains triterpenoids, cichoridiol and intybusoloid along with 11 known compounds namely lupeol, fridelin, $\beta$-sitosterol, stigmasterol, betulinic acid, betunaldehyde, syringic acid, vanilic acid, betulin, 6,7-dihydroxycoumarin and methyl- $\alpha$ D-galactopyranoside. ${ }^{6}$ Chicory fruits are one of the main ingredients of jigerine, a commercial product of India which is used for the treatment of various diseases of liver. ${ }^{7,8}$ Traditional uses, chemical constituents, pharmacological activities, toxicological studies, clinical trial reports, cultivation and sustainable uses of various anatomical parts of $C$. intybus has been reviewed by earlier researchers. ${ }^{9}$ Alcoholic extract of seeds of $C$. intybus has been reported to exhibit a potent antihepatotoxic activity on $\mathrm{CCl}_{4}$ induced liver damage in albino rats. ${ }^{10}$ The histopathological study has shown the normalization of the fatty accumulation of the tissues and resolvation of necrosis.? Investigation of the hepatoprotective activity of aqueous methanolic extract of C. intybus seed resulted in a significant reduction in death rate, serum levels of alkaline phosphatase, glutamyl oxaloacetate transaminase and glutamyl pyruvate transaminase against acetaminophen and $\mathrm{CCl}_{4}$ induced hepatic damage in mice. ${ }^{11}$ The aqueous extract of C. intibus seed showed significant antimicrobial activity against Staphylococcus aureus but not against Candida albicans. Ethyl acetate extract showed activity against Pseudomonas aeruginosa and Staphylococcus aureus. ${ }^{12}$ The present study is aimed at standardization the fruit of C. intybus and development of HPTLC finger profile for quality maintenance, authentication as well as scientific validation of this commercially important medicament.
Cite this article: Mandal AK, Shakila R, Divya KG, Rubeena M, Sunilkumar KN, Sathiyarajeswaran P. Pharmacognostical-physico-chemical Evaluation and Development of HPTLC Finger print for Cichorium intybus L. fruits. Pharmacog J. 2018;10(4):694-9. 


\section{MATERIALS AND METHODS}

\section{Material}

Cichorium intybus fruits were procured from local market of Mettur and was authenticated by Dr. M. Padma Sorna Subraminian, Research Officer (Botany), Siddha Medicinal Plants Garden, Mettur, Tamil Nadu.

\section{Macro-microscopy and powder microscopy}

The external features of the test sample were documented using Nikon COOLPIX 5400 digital camera followed by Zeiss Discovery.V8. For microscopy the sample was left in FAA (Formalin-5 ml + Acetic acid- $5 \mathrm{ml}$ $+70 \%$ Ethyl alcohol-90 ml) for more than $48 \mathrm{hr}$. The preserved specimens were hand cut into thin transverse section using 7 O'Clock platinum blades and were stained with safranine. Microsccopic features were photographed using Nikon ECLIPSE E200 trinocular microscope attached with Zeiss AxioCam ERc5s digital camera under bright field. The powdered sample was sieved through $\# 80$ mesh and a pinch of it was mounted on a microscopic slide with a drop of glycerin-water. Characters were observed using Nikon ECLIPSE E200 trinocular microscope attached with Zeiss AxioCam ERc5s digital camera under bright field. Diagnostic characters were captured, and photomicrographs were documented. Magnifications of the figures are indicated using pre-calibrated scale-bars.

\section{Physico-chemical analysis}

All the physico-chemical parameters were performed according to the method mentioned in standard books. ${ }^{13}$

\section{Sample preparation for HPTLC}

Exactly $2 \mathrm{~g}$ of coarse powder was taken in a Soxhlet apparatus and extracted with $100 \mathrm{ml}$ each of $n$-hexane, chloroform and ethanol successively. These extracts were filtered, concentrated over water bath and made up to $10 \mathrm{ml}$ with the corresponding solvents in standard flasks. The extracts were filled in separate sample vials of ATS 4 (CAMAG, Switzerland) for application.

\section{Chemicals, solvents and materials}

AR grade solvents $n$-hexane, chloroform, ethyl acetate, ethanol and formic acid were purchased from Merck. For visualizing purpose vanillin (1 g) sulphuric acid in ethanol (5\%) solution (VSA) was used. For HPTLC, automatic sampler 4, twin trough chamber $10 \times 10 \mathrm{~cm}$, TLC visualizer, TLC scanner 4, TLC plate heater (all from CAMAG, Switzerland) were used.

15 and $20 \mu \mathrm{l}$ of each extract were spotted using ATS 4 on silica gel $60 \mathrm{~F}_{254}$ coated aluminium plates $(6 \times 10 \mathrm{~cm})$ as $8 \mathrm{~mm}$ band width with $15 \mathrm{~mm}$ inter band distance. First application position was $15 \mathrm{~mm}$ and distance from the bottom of the plate was $10 \mathrm{~mm}$. Plates were developed using solvent systems with $n$-hexane - ethyl acetate - formic acid (7.5:2.5:0.5, $\mathrm{v} / \mathrm{v} / \mathrm{v})$, toluene - ethyl acetate - formic acid (6.5:4.0:0.5, v/v/v) and chloroform - methanol - formic acid (9:1: 0.8, v/v/v) for $n$-hexane, chloroform and ethanol extract respectively. The twin trough chamber was previously saturated for $15 \mathrm{~min}$ with the above mobile phases prior to development. The developed plates were dried, and photographs were taken by the visualizer under short UV and long UV. Scanning were performed by TLC Scanner 4 (Scanner_210441) under $\lambda 254$ and $\lambda$ $366 \mathrm{~nm}$ in absorbance mode ( $\mathrm{D}_{2}$ lamp) and fluorescence mode (Hg lamp) respectively with a slit dimension $6 \times 0.45 \mathrm{~mm}$ with scanning speed $20 \mathrm{~mm} / \mathrm{s}$. The scanned plates were dipped in VSA and heated over TLC plate heater at $105^{\circ} \mathrm{C}$ until the appearance of the coloured spots. Photographs were taken immediately at white light mode followed by scanning at $\lambda 520 \mathrm{~nm}$ at absorption mode (W lamp).

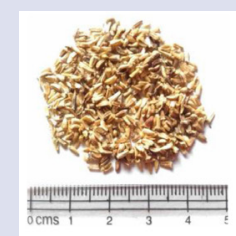

1.1 Dried fruits

Plate 1: Macroscopy Cichorium intybus L. fruit

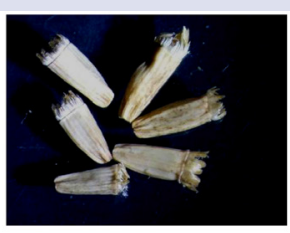

1.2 Fruits enlarged

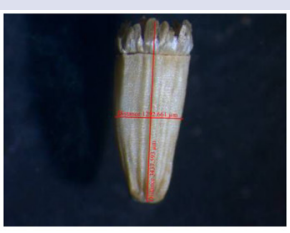

Cichorium intybus L. fruit

\section{RESULT AND DISCUSSION}

\section{Macroscopy}

Macroscopically, the fruit of C. intybus is creamish - brown in colour, measures up to 3 to $3.5 \mathrm{~mm}$ in length and about $1.25 \mathrm{~mm}$ in breadth; oblong in shape pointed towards base and broader towards upper side; topped with scaly pappus derived from accrescent calyx; surface smooth and shining and comprises of about 8 ridges (Plate 1); odour and taste nil.

\section{Microscopy}

The pericarp of fruit consists of a single epidermal layer which bears randomly distributed groups of unicellular papillose trichomes; the outer mesocarp shows 3 to 4 layers of sclerenchymatous cells arranged beneath the epidermal cells while bulk of sclerenchymatous cells arranged under elevated areas giving the appearance of ridges and furrows; the inner mesocarp is made up of large compactly arranged columnar cells followed by thin layer compressed cells forming endocarp enclosing two cotyledons. Endocarp and testa are fused and cannot be differentiated as the fruit is an achene. The cotyledon has a thin walled parenchymatous epidermis enclosing parenchyma cells containing globoid aluerone grains (Plate 2).

\section{Powder microscopy}

Powder shows polygonal epicarp cells in surface and oblique views; pitted as well as normal parenchyma; parenchyma containing oil globules; cells of cotyledons containing aleurone grains; bundle of fibre and pitted vessels (Plate 3); odor and taste nil.

\section{Physico-chemical analysis}

Moisture plays animportant role in deterioration of a drug due to microbial load leading to decline in shelf life. The loss on drying value which indicates the presence of moisture content of air dried sample was found to be $3.43 \%$. Total ash which indicate the total inorganic content including physiological and non-physiological salts of the drug was estimated to be as $9.98 \%$. Water soluble ash which predicts the water soluble inorganic salts was calculated as $1.93 \%$. The acid insoluble ash, majorly composed of silica in a plant drug, was found to be $1.60 \%$. The water and ethanol soluble extractive value which indicate the solubility of the active ingredients of the plant in water and ethanol respectively were estimated to be $9.85 \%$ and $11.25 \%$. The $\mathrm{pH}$ of the drug was determined as 5.86 which indicates the acidic nature of the plant (Table 1).

\section{TLC Photo documentation}

TLC finger print profile of $n$-hexane extract of Cichorium intybus L. fruits revealed 6 bands with $\mathrm{R}_{\mathrm{f}} 0.18,0.29,0.37,0.49,0.58$ and 0.75 (green) under short UV; 6 spots with $\mathrm{R}_{\mathrm{f}} 0.23,0.29,0.36$ (red), 0.42 (fluorescent blue), 0.55 and 0.63 (blue) under long UV; 8 spots with $\mathrm{R}_{\mathrm{f}} 0.06,0.14$ (violet), 0.17 (ash), 0.32 (violet), 0.45, 0.53, 0.75 and 0.82 (purple) under white light (post derivatization) (Figure 1). Successive chloroform extract showed 6 bands with $\mathrm{R}_{\mathrm{f}} 0.10,0.21,0.32,0.51,0.73$ and 0.79 (green) under short UV; 7 bands with $\mathrm{R}_{\mathrm{f}} 0.14,0.21,0.28$ (blue), 0.32 (red), 0.53 

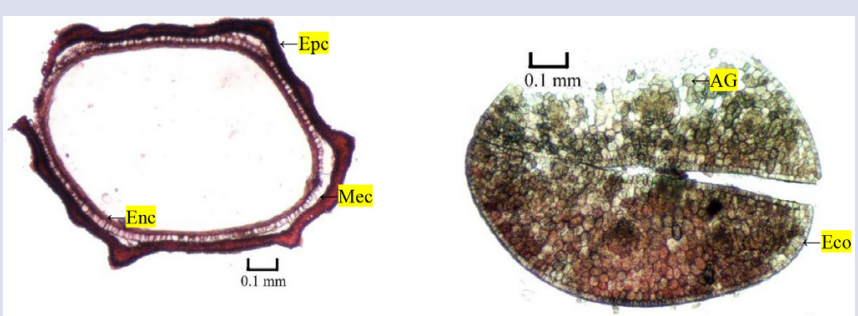

2.1 TS of entire fruit

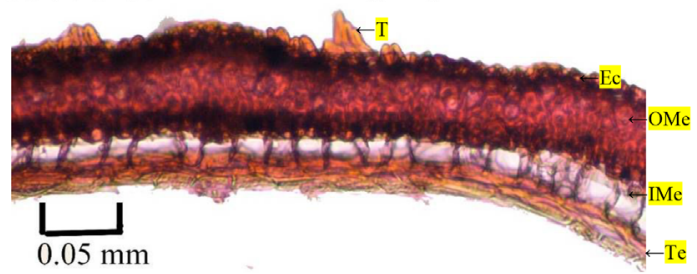

2.3 A region of pericarp enlarged

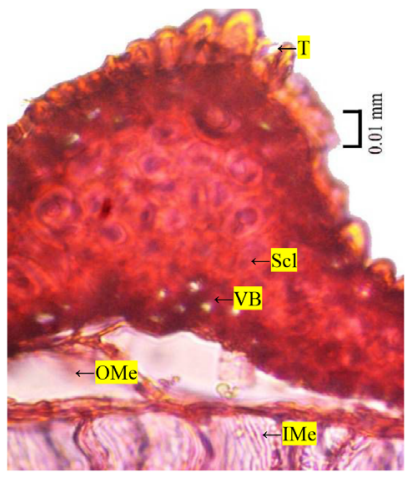

2.4 A region of pericarp TS through ridge

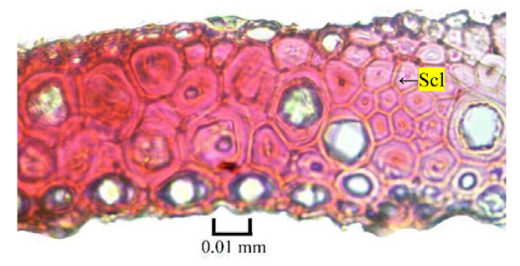

2.5 TS of sclrenchyma of outer mesocarp

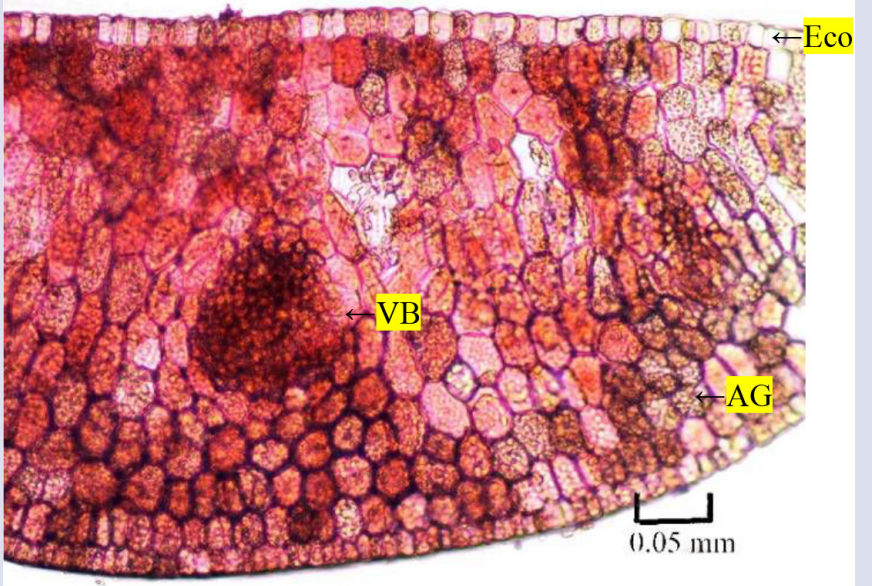

\subsection{A portion of TS through cotyledon enlarged}

Plate 2: Microscopy Cichorium intybus fruit.

AG - Aleurone grains; Ec - Epicarp; Eco - Epidermis of cotyledon; Enc - Endocarp; IMe - Inner mesocarp; Mec - Mesocarp; OMe - Outer mesocarp; Scl - Sclerenchyma; Te - Testa; T - Trichome; VB - Vascular bundle.

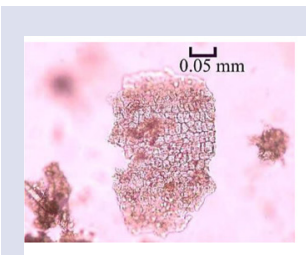

3.1 Epicarp in surface view

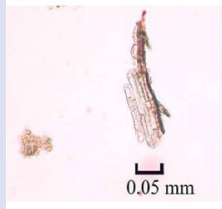

3.4 Parenchyma

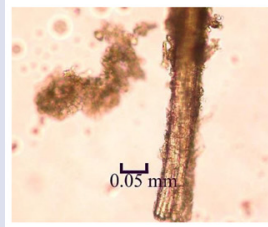

3.7 Fibre bundle

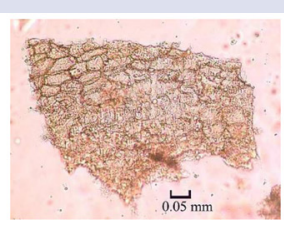

3.2 Pitted parenchyma

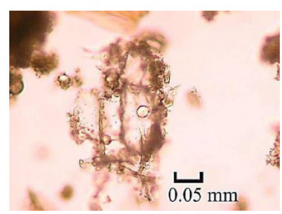

3.5 Parenchyma with oil globules

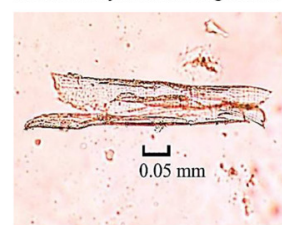

3.8 Pitted vessel

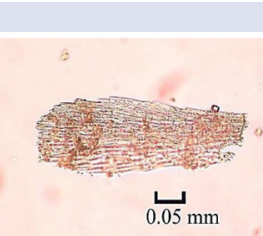

3.3 Epicarp in oblique view
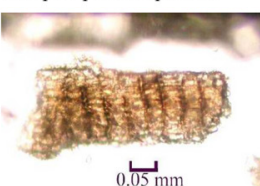

Plate 3: Microscopy of powder of Cichorium intybus fruit

Table 1: Physico-chemical constants of Cichorium intybus fruits.

\begin{tabular}{cc}
\hline Parameter & Result \\
\hline Loss on drying at $105^{\circ} \mathrm{C}$ & $3.43 \%$ \\
Total ash & $9.98 \%$ \\
Water soluble ash & $1.93 \%$ \\
Acid insoluble ash & $1.60 \%$ \\
Water soluble extractive & $9.85 \%$ \\
Ethanol soluble extractive & $11.25 \%$ \\
pH & 5.86 \\
Successive Extraction & $1.70 \%$ \\
Chloroform & $1.25 \%$ \\
Ethanol & $3.25 \%$ \\
\hline
\end{tabular}

(violet), 0.64 and 0.73 (red) under long UV; 10 spots with $\mathrm{R}_{\mathrm{f}} 0.07,0.09$ (violet), 0.14 (grey), 0.16, $0.37,0.54$ (purple), 0.61, 0.70, 0.75 and 0.81 (violet) under white light (post derivatization) (Figure 2). In case of successive ethanol extract of 6 bands with $R_{f} 0.04,0.11,0.22,0.37,0.53$, 0.85 (green) were found under short $\mathrm{UV}, 6$ spots with $\mathrm{R}_{\mathrm{f}} 0.11,0.34$ (blue), 0.40 (fluorescent blue), 0.58 (blue), 0.82 and 0.90 (red) were seen under long UV and 9 bands with $\mathrm{R}_{\mathrm{f}} 0.18$ (grey), $0.21,0.36$ (violet), 0.49 (brown), $0.53,0.66,0.74,0.79$ and 0.93 (violet) were found under white light (post derivatization) (Figure 3 ). The $\mathrm{R}_{\mathrm{f}}$ values and corresponding colours of the bands are enlisted in for $n$-hexane, chloroform and ethanol extract respectively (Table 2).

\section{HPTLC denistometric scan}

The fingerprint profile of $n$-hexane extract under $\lambda 254 \mathrm{~nm}$ revealed that the major peak is $\mathrm{R}_{\mathrm{f}} 0.58$ with an area of $18.52 \%$ followed by the peaks at $\mathrm{R}_{\mathrm{f}} 0.29(17.38 \%), \mathrm{R}_{\mathrm{f}} 0.37(9.39 \%)$ and 9 more minor peaks (Figure 4.1); under $\lambda 366 \mathrm{~nm}$, the major peak appeared at $\mathrm{R}_{\mathrm{f}} 0.36$ with an area $32.01 \%$, second major peak at $R_{f} 0.42$ with an area $23.77 \%$ followed by $R_{f}$ 0.29 with an area of $13.72 \%$ along with 8 more peaks (Figure 4.2 ); under white light after derivatization, the peak at $\mathrm{R}_{\mathrm{f}} 0.75$ with an area $25.22 \%$ 
Table 2: $\mathbf{R}_{\mathrm{f}}$ values and color of spots of extracts of Cichorium intybus fruits.

\begin{tabular}{|c|c|c|c|c|c|c|}
\hline \multirow{2}{*}{$\begin{array}{l}\text { Name of the } \\
\text { extract }\end{array}$} & \multicolumn{2}{|c|}{ UV 254 nm } & \multicolumn{2}{|c|}{ UV $366 \mathrm{~nm}$} & \multicolumn{2}{|c|}{ White light after derivatization } \\
\hline & $R_{f}$ & Colour & $R_{f}$ & Colour & $R_{f}$ & Colour \\
\hline \multirow[t]{9}{*}{ n-Hexane } & Green & 0.18 & Blue & 0.06 & Violet & 0.06 \\
\hline & Green & 0.27 & Blue & 0.09 & Violet & 0.11 \\
\hline & Green & 0.31 & Red & 0.22 & Violet & 0.13 \\
\hline & Green & 0.35 & Red & 0.28 & Grey & 0.17 \\
\hline & Green & 0.48 & Red & 0.35 & Violet & 0.30 \\
\hline & Green & 0.60 & F Blue & 0.41 & Purple & 0.44 \\
\hline & Green & 0.73 & Blue & 0.53 & Purple & 0.54 \\
\hline & & & Blue & 0.62 & Purple & 0.74 \\
\hline & & & & & Purple & 0.83 \\
\hline \multirow[t]{10}{*}{ Chloroform } & Green & 0.10 & Blue & 0.13 & Violet & 0.06 \\
\hline & Green & 0.21 & Blue & 0.21 & Violet & 0.09 \\
\hline & Green & 0.32 & Blue & 0.28 & Grey & 0.14 \\
\hline & Green & 0.51 & Red & 0.32 & Grey & 0.16 \\
\hline & Green & 0.73 & Violet & 0.52 & Purple & 0.37 \\
\hline & Green & 0.80 & Red & 0.64 & Purple & 0.53 \\
\hline & & & Red & 0.74 & Violet & 0.62 \\
\hline & & & & & Violet & 0.69 \\
\hline & & & & & Violet & 0.75 \\
\hline & & & & & Violet & 0.82 \\
\hline \multirow[t]{9}{*}{ Ethanol } & Green & 0.05 & Blue & 0.11 & Grey & 0.19 \\
\hline & Green & 0.12 & Blue & 0.34 & Violet & 0.22 \\
\hline & Green & 0.20 & F Blue & 0.42 & Violet & 0.36 \\
\hline & Green & 0.36 & Blue & 0.60 & Brown & 0.50 \\
\hline & Green & 0.55 & Red & 0.68 & Violet & 0.53 \\
\hline & Green & 0.86 & Red & 0.85 & Violet & 0.66 \\
\hline & Green & 0.93 & Red & 0.92 & Violet & 0.74 \\
\hline & & & & & Violet & 0.80 \\
\hline & & & & & Violet & 0.94 \\
\hline
\end{tabular}

F - Fluorescent

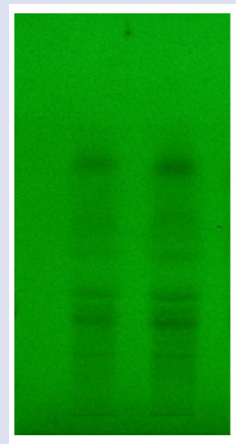

1.1 Under short UV

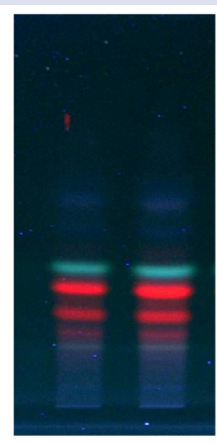

1.2 Under long UV

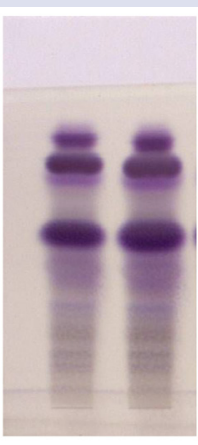

1.3 White light after derivatization

Figure 1: Photo documentation of $n$-hexane extract of Cichorium intybus fruit.

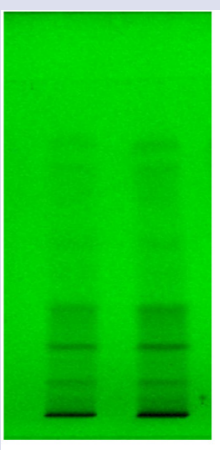

2.1 Under short UV

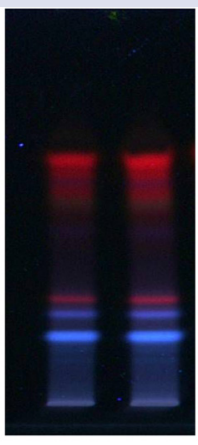

2.2 Under long UV

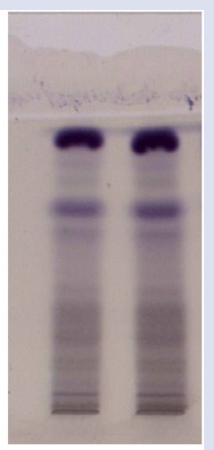

2.3 White light after derivatization
Figure 2: Photo documentation of chloroform extract of Cichorium intybus L. fruit. 


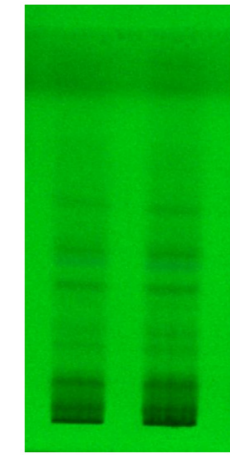

3.1 Under short UV

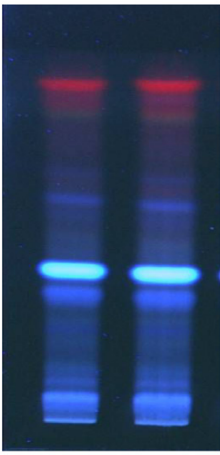

3.2 Under long UV

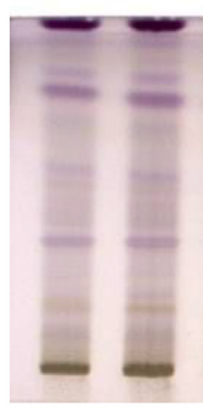

3.3 White light after derivatization
Figure 3: Photo documentation of ethanol extract of Cichorium intybus L. fruit.

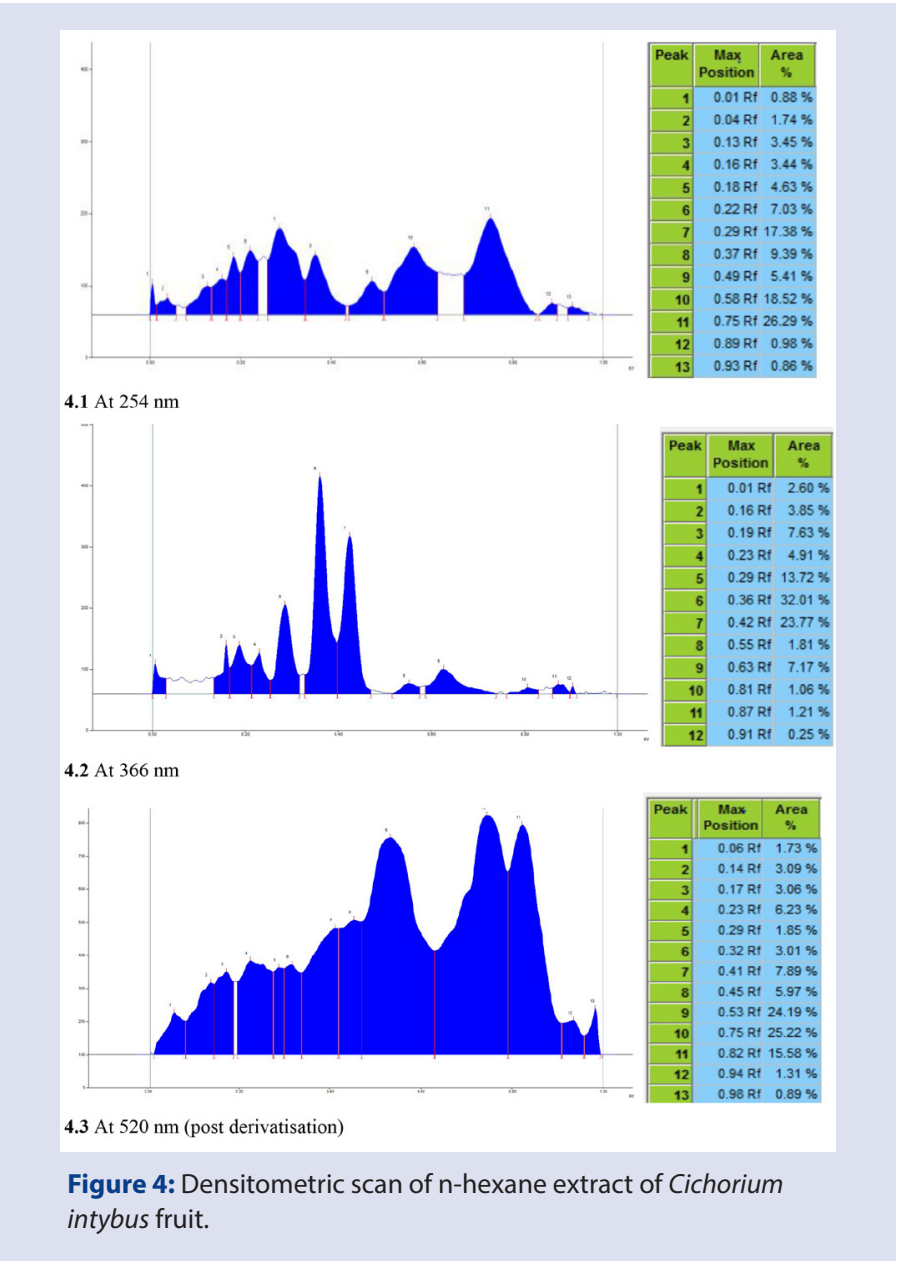

came out as the major followed by the peak at $\mathrm{R}_{\mathrm{f}} 0.53(24.19 \%)$ and $\mathrm{R}_{\mathrm{f}}$ 0.8215 .58 (15.58\%) along with 9 more minor peaks (Figure 4.3). The finger print profile of successive chloroform extract showed the major peak at $R_{f} 0.32$ with an area of $30.28 \%$ followed by $R_{f} 0.21(16.71 \%), R_{f} 0.79$ (9.62\%) along with 7 more minor peaks (Figure 5.1) under $\lambda 254 \mathrm{~nm}$; under $\lambda 366 \mathrm{~nm}$ the major peak appeared at $R_{f} 0.73$ with an area $30.21 \%$ followed by the peak at $R_{f} 0.21$ with an area $30.03 \%$ along with 9 more peaks (Figure 5.2); under white light the fingerprint profile showed

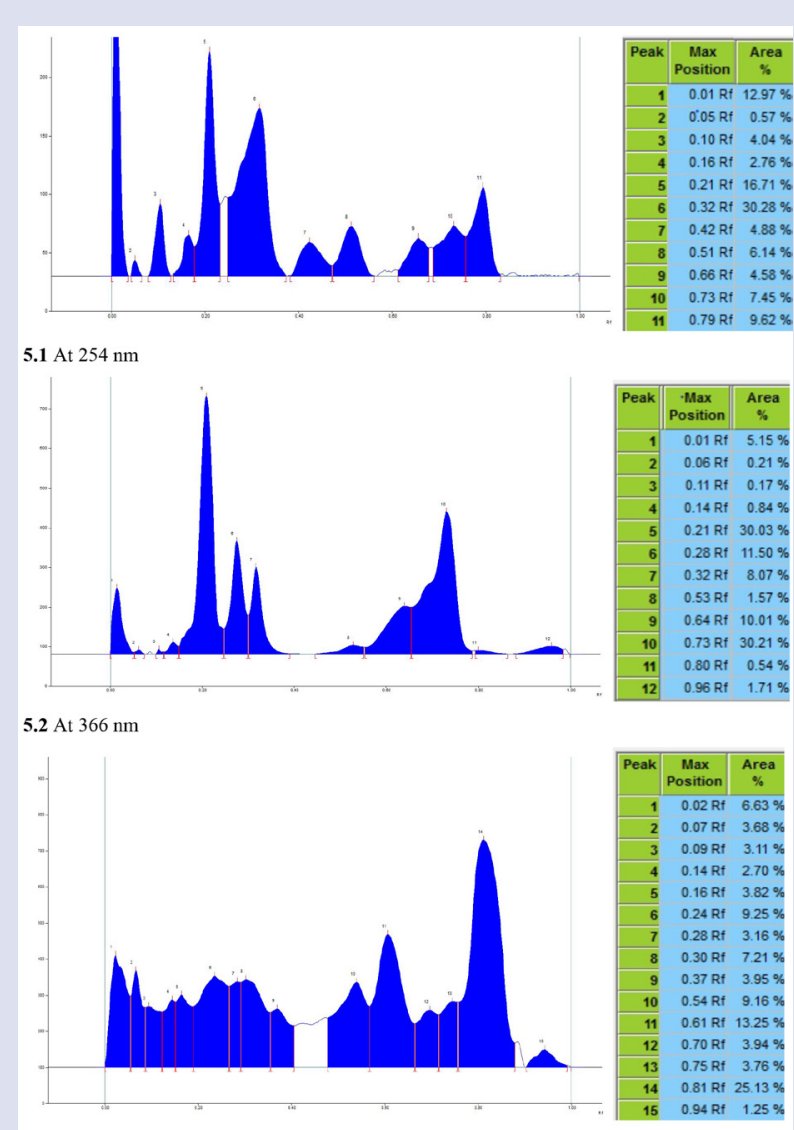

5.3 At $520 \mathrm{~nm}$ (post derivatisation)

Figure 5: Densitometric scan of chloroform extract of Cichorium intybus fruit.

the major peak at $\mathrm{R}_{\mathrm{f}} 0.81$ with an area $25.13 \%$, whereas the peak having $R_{f} 0.61$ with an area $13.25 \%$ was second major and the peak having $R_{f}$ 0.24 with an area $9.25 \%$ was the third major peak. It also showed 11 more minor peaks (Figure 5.3). The finger print profile of successive ethanol extract under $\lambda 254 \mathrm{~nm}$ showed the major peak at $\mathrm{R}_{\mathrm{f}} 0.85$ with an area of $15.67 \%$ followed by $\mathrm{R}_{\mathrm{f}} 0.90(12.67 \%), \mathrm{R}_{\mathrm{f}} 0.42(12.03 \%)$ along with 10 more minor peaks (Figure 6.1); under $\lambda 366 \mathrm{~nm}$, the major peak appeared at $R_{f} 0.40$ with an area $53.75 \%$ followed by the peak at $R_{f} 0.34$ with an area $15.19 \%$ along with 7 more peaks (Figure 6.2); under white light, the fingerprint profile showed the major peak at $R_{f} 0.93$ with an area $26.87 \%$, whereas the peak having $R_{f} 0.74$ with an area $15.00 \%$ was second major and the peak having $\mathrm{R}_{\mathrm{f}} 0.89$ with an area $11.52 \%$ was the third major peak; it showed 12 more minor peaks (Figure 6.3).

\section{CONCLUSION}

Cichorium intybus fruit (chicory seed) is an important ingredient of several Ayurveda, Siddha, Unani and other traditional formulations for the treatment of various ailments. The current attempt of preparation of monograph including macro-microscopy, powder microscopy, physicochemical standardisation, TLC finger print profiles will help to check the quality of the drug prior to its use in traditional medicine.

\section{ACKNOWLEDGEMENT}

The authors extend their heartfelt thanks to Director General, CCRS for the support and Dr. Padma Sorna Subramanian, Research Officer (Botany), Medicinal Plant Garden, Mettur, for providing authentic samples. 


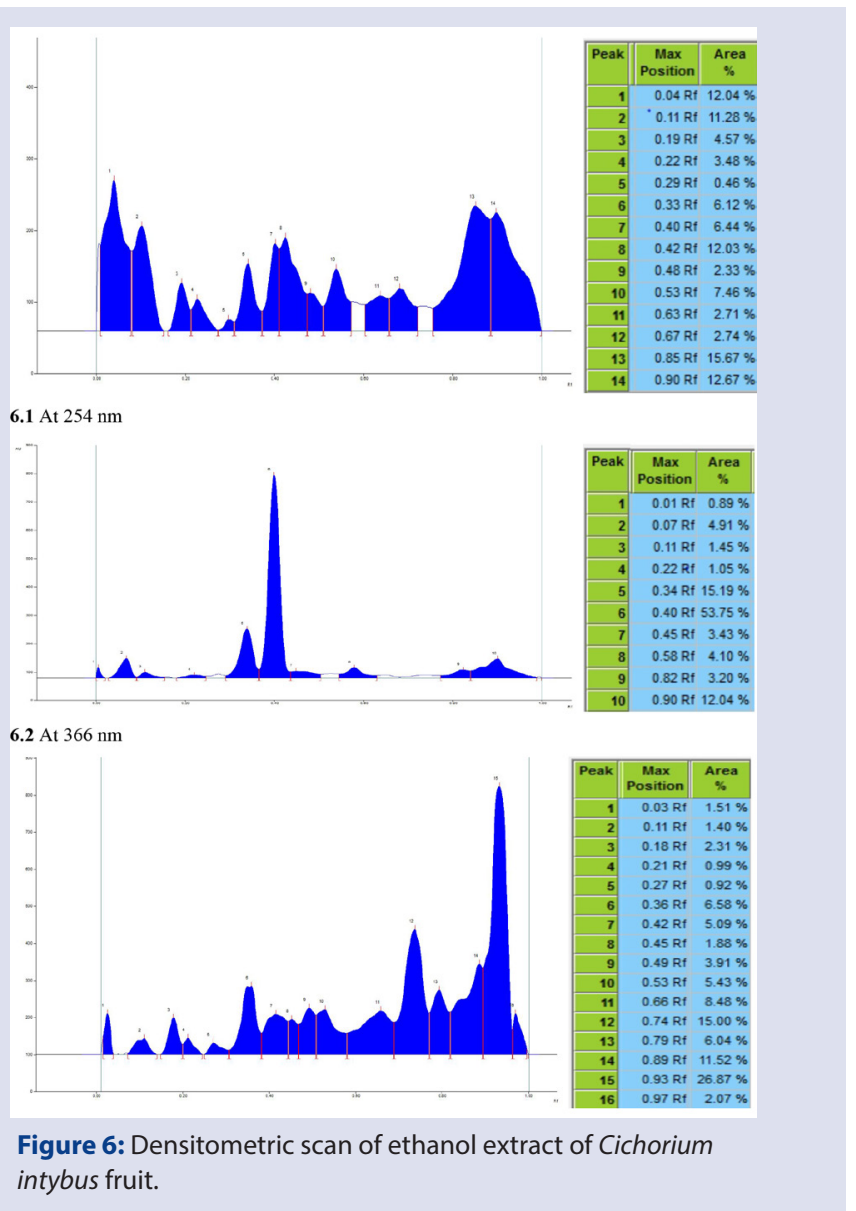

\section{CONFLICT OF INTEREST}

We declare no conflict interest with any.

\section{ABBREVIATIONS}

AG: Aleurone grains; Ec: Epicarp; Eco: Epidermis of cotyledon; Enc: Endocarp; IMe: Inner mesocarp; Mec: Mesocarp; OMe: Outer mesocarp; Scl: Sclerenchyma; Te: Testa; T: Trichome; VB: Vascular bundle.

\section{REFERENCES}

1. Quality Standards of Indian Medicinal Plants, New Delhi: Indian Council of Medical Research. 2005;3:126.

2. Bias HP, Ravishankar GA. Cichorium intybus L.- cultivation, processing, utility, value adiition and biotechnology, with an emphasis on current status and future prospects. Journal of the Science of Food and Agriculture. 2001;81(5):467-84.

3. Vanwyk BE, Van Oudtshoorn B, Gericke N. Medicinal Plants of South Africa, Briza Publications, Pretoria, South Africa. 1997

4. European Medicines Agency, "Assessment report on Cichorium intybus L., radix," EMA/HMPC/113041/2010,2013.

5. Nandagopal S, Ranjithakumari BD. Phytochemical and antibacterial studies of Chicory (Cichorium intibus) a multipurpose medicinal plant. Advances in Biological Research. 2007;(1-2):17-21.

6. Rahman A, Zareen S, Choudary MI, Akhtar MN, Khan SN. Alpha-glucosidase inhibitory activity of triterpenoids from Cichorium intybus. J Nat Prod. 2008;71(5):910-13

7. Ahmed B, Al-Howiriny TA, Siddiqui AB. Antihepatotoxic activity of seeds of Cichorium intybus. J Ethnopharmacol. 2003;87(2-3):237-40.

8. Najmi AK, Pillai KK, Pal SN, Aqil M. Free radical scavenging and hepatoprotective activity of jigrine against galactosamine induced heptatopathy in rats. $J$ Ethanopharmacol. 2005;97(3):521-5.

9. Street RA, Sidan J, Prinsloo G. Cichorium intybus: Traditional uses, phytochemistry, pharmacology and toxicology. Evidence-Based Complementary and Alter native Medicine. 2013;13. pages. http://dx/doi.org/10.1155/2013/579319.

10. Gadgoli C, Mishra SH. Antihepatotoxic activity of Cichorium intybus. J Ethanopharmacol. 1997;58(2):131-4

11. Gilani AH, Janbaz KH. Evaluation of the liver protective potential of Cichorium intybus seed extract on acetaminophen and $\mathrm{CCl}_{4}$ - induced damange. Phytomedicine. 1994;1(3):193-7.

12. Shaikh T, Rub Ra, Sasikumar S. Antimicrobial screening of Cichorium intibus seed extracts. Arabian Journal of Chemistry. 2016;9:S1569-S73.

13. Anonymous. Quality control Methods for medicinal plant materials. World Health Organizing, Geneva. 1998.
GRAPHICAL ABSTRACT

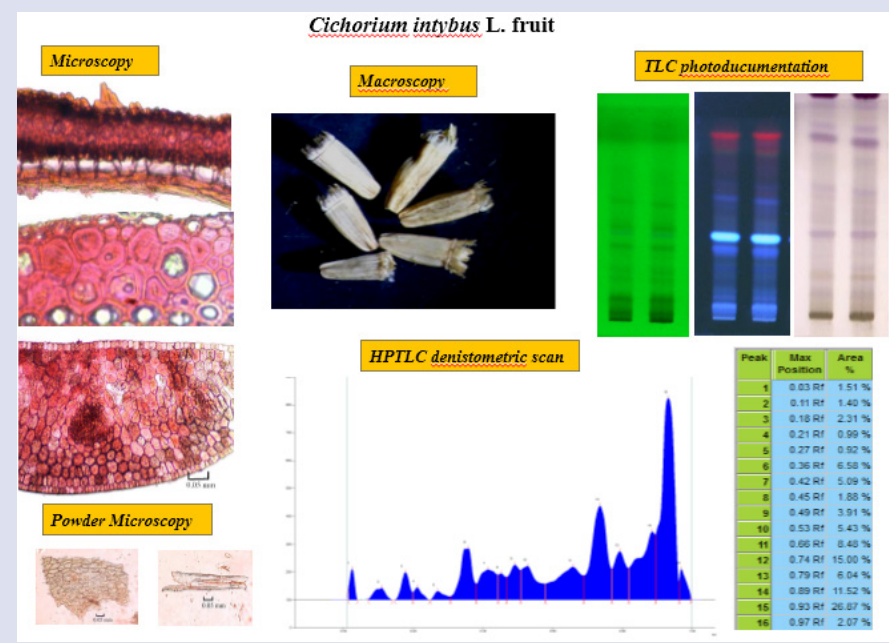

\section{SUMMARY}

- $\quad$ Cichorium intybus fruit (chicory seed) is an important ingredient of several Ayurveda, Siddha, Unani and other traditional formulations for the treatment of various ailments.

- $\quad$ The current attempt of preparation of monograph including macro-microscopy, powder microscopy, physico-chemical standardisation, TLC finger print profiles will help to check the quality of the drug prior to its use in traditional medicine.

\section{ABOUT AUTHORS}

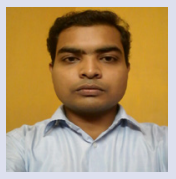

Mandal AK: Is working as Research Assistant (Chemistry) at Siddha Central Research Institute, Arumbakkam, Chennai-106 from 2016 onwards.

Shakila R: Is working as Research Officer (Chemistry) at Siddha Central Research Institute, Arumbakkam, Chennai-106 from 2010 onwards.

Cite this article: Mandal AK, Shakila R, Divya KG, Rubeena M, Sunilkumar KN, Sathiyarajeswaran P. Pharmacognostical-physicochemical Evaluation and Development of HPTLC Finger print for Cichorium intybus L. fruits. Pharmacog J. 2018;10(4):694-9. 